\title{
Effect of Bare-Metal Nitinol Stent Implantation and Paclitaxel-Eluting Nitinol Stent Implantation on Vascular Response in the Superficial Femoral Artery Lesion Assessed on Intravascular Ultrasound
}

\author{
Kojiro Miki, MD; Kenichi Fujii, MD; Daizo Kawasaki, MD; Masashi Fukunaga, MD; \\ Machiko Nishimura, MD; Tetsuo Horimatsu, MD; Ten Saita, MD; Hiroto Tamaru, MD; \\ Takahiro Imanaka, MD; Masahiko Shibuya, MD; Motomaru Masutani, MD; \\ Mitsumasa Ohyanagi, MD; Tohru Masuyama, MD
}

\begin{abstract}
Background: Although previous intravascular ultrasound (IVUS) studies reported that the drug-eluting stent (DES) has successfully decreased in-stent restenosis (ISR) by inhibiting neointimal hyperplasia (NIH) in the coronary artery lesion, no IVUS data for vascular response after DES implantation in the superficial femoral artery (SFA) have been published.
\end{abstract}

Methods and Results: We retrospectively analyzed 38 de novo SFA lesions from 32 patients who underwent en-
dovascular therapy (EVT) with self-expanding bare-metal nitinol stent ( 25 lesions; BMS group) or self-expanding
paclitaxel-eluting nitinol stents (13 lesions; PES group). At 6 months after EVT, follow-up IVUS was done to evaluate
$\mathrm{NIH}$. Serial IVUS volumetric analysis was done after stent deployment and at follow-up. Mean stent, lumen and
neointimal areas were calculated as the volume divided by the stent length. The primary endpoint of this study was
mean late lumen loss at 6 -month follow-up. The mean follow-up period was $189 \pm 39$ days. Mean neointimal area was
smaller in the PES group compared to the BMS group ( $3.3 \pm 1.0 \mathrm{~mm}^{2}$ vs. $\left.10.2 \pm 4.1 \mathrm{~mm}^{2}, \mathrm{P}<0.001\right)$. Mean late lumen
loss was significantly lower in the PES group compared to the BMS group $\left(-2.3 \pm 3.7 \mathrm{~mm}^{2} \mathrm{vs} .2 .1 \pm 4.7 \mathrm{~mm}^{2}, \mathrm{P}<0.05\right)$.

Conclusions: EVT with DES in SFA lesions might decrease NIH associated with ISR in short-term follow-up.

(Circ J 2014; 78: 1451-1458) Key Words: Endovascular therapy; Intravascular ultrasound; Paclitaxel-eluting nitinol stent; Restenosis; Superficial
femoral artery

$\mathbf{E}$ ndovascular therapy (EVT) has been accepted widely as a minimally invasive treatment for patients with peripheral artery disease due to the effectiveness and the development of techniques and devices. ${ }^{1-3}$ In femoropopliteal artery lesions, EVT with self-expanding bare-metal nitinol stent (BMS) produces better clinical outcome compared to that with balloon angioplasty. ${ }^{4} \mathrm{~A}$ previous study reported that the primary patency rate of the superficial femoral artery (SFA) lesions treated with BMS is approximately $84 \%$ at 1 year. ${ }^{5}$ In contrast, the main limitation of the percutaneous revascularization with stent implantation remains the phenomenon of restenosis, which is an exaggerated healing response to the vessel wall injury that occurs as a result of mechanical dilatation. Recent clinical study suggested that restenosis rate after stent implantation in the SFA lesions is approximately $45 \%$ at 2 years. ${ }^{6}$ Based on such a background, the self-expanding paclitaxel-eluting nitinol stent (PES; Zilver PTX; Cook Medical, Bloomington, IN, USA) has recently become available for the treatment of femoropopliteal lesions, and superior clinical outcomes after EVT with PES have been reported. ${ }^{7,8}$ The primary patency rate after PES implantation is reported as $90 \%$ at 1 year. ${ }^{7}$ The difference in the mechanisms underlying the vascular response after PES and BMS, however, is poorly understood. The purpose of the present study was to evaluate the

Received December 13, 2013; revised manuscript received February 16, 2014; accepted February 18, 2014; released online April 9, 2014 Time for primary review: 13 days

Cardiovascular Division (K.M., K.F., M.F., M.N., T.H., T.S., H.T., T.I., M.S., T.M.), Division of Coronary Heart Disease (M.M., M.O.), Hyogo College of Medicine, Nishinomiya; Cardiovascular Center, Morinomiya Hospital, Osaka (D.K.), Japan

Mailing address: Kenichi Fujii, MD, Cardiovascular Division, Hyogo College of Medicine, 1-1 Mukogawa-cho, Nishinomiya 663-8501, Japan. E-mail: kfujii@hyo-med.ac.jp

ISSN-1346-9843 doi:10.1253/circj.CJ-13-1508

All rights are reserved to the Japanese Circulation Society. For permissions, please e-mail: cj@j-circ.or.jp 
chronic vascular response to the implantation of PES and BMS in SFA lesions using serial volumetric intravascular ultrasound (IVUS).

\section{Methods}

\section{Patient and Lesions}

All of the patients suffered from symptoms due to SFA lesions (Rutherford 2-5) that affected quality of life despite exercise and optimal medication. De novo SFA lesions treated with the SMARTControl ${ }^{\mathrm{TM}}$ stent (Cordis, Miami Lakes, FL, USA) or Zilver PTX stent at the Hyogo College of Medicine between September 2010 and January 2013 were retrospectively enrolled in this study. Patients with acute or subacute limb ischemia, a history of lower extremity bypass surgery, and untreated aorto-iliac artery disease were excluded from analysis. The study protocol was approved by the institutional review board of Hyogo College of Medicine. All patients signed specific written informed consent describing the follow-up angiography and IVUS.

\section{Procedures}

After the initial diagnostic angiography of the lower limb, indications for EVT were decided by more than 2 physicians. Approach for EVT was determined at the operator's discretion. After insertion of a 6-Fr sheath, unfractionated heparin (5,000 units) was given into the artery. The anticoagulation was accomplished by measurement of the activated clotting time within 250-300 s during EVT. After a 0.014/0.018-inch guidewire was advanced down to the lesion, pre-dilation was performed by the balloon with a diameter equal to the reference vessel diameter according to the visual estimation. When flow-limiting dissections or recoils caused a stenosis $>30 \%$, BMS or PES was implanted. Until June 2012, BMS have been used as a default strategy for every EVT at Hyogo College of Medicine. From July 2012, PES became commercially available, replacing BMS as the strategy of choice in every EVT because of effectiveness considerations. Therefore, BMS were implanted before July 2012 and PES were implanted after June 2012. Stent diameter that was 1-2 mm larger than the reference vessel diameter at proximal sites of the lesions on angiographic visual estimation was chosen. When multiple stents were required, the margin of the overlapping stent was $<10 \mathrm{~mm}$. Post-dilation was performed routinely in all lesions with a balloon of 5-mm diameter at a pressure of 14 atm $\left(14.2 \times 10^{5} \mathrm{~Pa}\right)$. Dual anti-platelet therapy (DAPT; aspirin $100 \mathrm{mg} /$ day and cilostazol $100 \mathrm{mg} /$ day, or clopidogrel $75 \mathrm{mg}$ / day) was started at least 1 week prior to EVT and continued during the follow-up period. Procedural success was defined as residual stenosis $<30 \%$ and the absence of flow-limiting dissection on angiography.

\section{Quantitative Vascular Angiography (QVA) and Stent Fracture}

Angiography was obtained before EVT, immediately after EVT, and at 6-month follow-up with anteroposterior and/or oblique view. QVA analysis using commercially available software (CAAS 5.9; Pie Medical Imaging, Maastricht, The Netherlands) was done to determine lesion severity and to evaluate neointimal hyperplasia (NIH) at follow-up in a blinded fashion. The tip of the guiding catheter was not available as a calibration in QVA analysis because the movement of the catheterization table was required for angiographic evaluation for the entirety of the SFA lesions. It was, therefore, impossible to accurately measure the absolute values of reference vessel, minimum lumen, and in-stent minimum lumen diameters.
Only the percent diameter stenosis (\%DS) was calculated as a ratio of the minimum lumen diameter or the in-stent minimum lumen diameter to the average [(proximal+distal $) \times 1 / 2]$ reference vessel diameter. ${ }^{9}$ Angiographic restenosis was defined as recurrence of $>50 \%$ DS as determined on QVA analysis within the stented segment or within the 5-mm segment proximal or distal to the stent edge. Stent fracture was assessed on X-ray at 6 months after stent implantation. Stent fracture was defined as clear interruption of stent struts identified on X-ray from multiple projections.

\section{IVUS Imaging Protocol}

IVUS was done in all cases with a commercially available IVUS console ( $5^{\mathrm{TM}}$ Imaging System; Volcano, Rancho Cordova, CA, USA) and a phased-array 20-MHz IVUS catheter (Eagle Eye Gold; Volcano). At the end of the initial procedure and at 6-month follow-up, a slow pullback was performed from distal to proximal reference sites through the stented segment. A manual pullback at a constant speed of $10 \mathrm{~mm} / \mathrm{s}$ was performed after initial deployment and at follow-up.

\section{Serial 2-D IVUS}

All IVUS images were reviewed and quantitative IVUS analysis was performed using computed planimetry (EchoPlaque; Indec Systems, Santa Clara, CA, USA) by an independent experienced observer who was blinded to the clinical and angiographic information. Image slices were obtained at 5-mm axial intervals throughout the entire segment including stented and proximal and distal references sites, and stent and lumen borders were manually traced in all image slices. The image slices with the minimum lumen area (MLA), minimum stent area (MSA), and maximum stent area were selected from all image slices. The proximal and distal reference segments were selected as the most normal-looking cross-sections within the same arterial segment (typically, $<10 \mathrm{~mm}$ proximal and distal to the stents), but before any large side branch. Proximal and distal reference segment external elastic membrane (EEM) area, lumen area, and plaque burden [(EEM area-lumen area)/ EEM area] were measured. Stent expansion ratio was calculated as MSA/[(proximal reference lumen area+distal reference lumen area) $\times^{1 / 2}$ ]. Radial stent symmetry index was minimum/ maximum stent diameter. Axial stent symmetry index was minimum/maximum stent area. ${ }^{10}$ The smallest radial stent symmetry index and axial stent symmetry index from all image slices within the stents were selected for analysis. In the follow-up IVUS analysis, neointimal (stent-lumen) area was also calculated within the stented segment. Percent neointimal area (\%NIA) was defined as NIA divided by stent area. To assess reproducibility of volumetric IVUS measurements, intra- and inter-observer variability analysis was performed with quantitative measurements of stent area, lumen area, and NIA at follow-up from 50 randomly selected cross-sections in 10 patients. The images were re-measured by 1 observer for the intra-observer variability at 2 separate time points. The inter-observer variability was determined by the measurements conducted by 2 independent observers.

Qualitative parameters assessed in the study included: (1) stent edge dissection (defined as a disruption of the vessel luminal surface at the stent edges with visible flap $\left.{ }^{11}\right)$; (2) tissue protrusion after stent deployment (defined as protrusion of tissue between stent struts extending inside a circular arc connecting adjacent struts on IVUS images ${ }^{10}$ ); and (3) thrombus at follow-up (defined as a low echoic mass, often mobile and extruding into the vessel lumen and sometimes becoming detached from the vessel wall ${ }^{12}$ ). 


\begin{tabular}{|c|c|c|c|}
\hline & BMS $(n=25)$ & $\operatorname{PES}(n=13)$ & P-value \\
\hline Age (years) & $74.9 \pm 9.4$ & $75.1 \pm 7.4$ & 0.96 \\
\hline Female & $3(12)$ & $3(23)$ & 0.39 \\
\hline Body mass index & $22.9 \pm 3.7$ & $24.0 \pm 4.7$ & 0.41 \\
\hline Hypertension & $22(88)$ & $11(85)$ & $>0.99$ \\
\hline Dyslipidemia & $21(84)$ & $8(62)$ & 0.23 \\
\hline Diabetes mellitus & $13(52)$ & $10(77)$ & 0.18 \\
\hline Smoker & $8(32)$ & $1(8)$ & 0.13 \\
\hline Chronic renal disease & $19(76)$ & $8(62)$ & 0.46 \\
\hline Coronary artery disease & $11(44)$ & $7(54)$ & 0.73 \\
\hline Cerebral vascular disease & $7(28)$ & $5(38)$ & 0.71 \\
\hline Ankle brachial index & $0.67 \pm 0.12$ & $0.68 \pm 0.18$ & 0.88 \\
\hline Critical limb ischemia & $4(16)$ & $1(8)$ & 0.64 \\
\hline \multicolumn{4}{|l|}{ Anti-platelet therapy } \\
\hline Aspirin and clopidogrel & $3(12)$ & $8(62)$ & $<0.01$ \\
\hline Aspirin and cilostazol & $21(84)$ & $4(31)$ & $<0.01$ \\
\hline Lesion length (mm) & $142.8 \pm 86.5$ & $169.2 \pm 98.0$ & 0.40 \\
\hline Chronic total occlusion & $8(32)$ & $8(62)$ & 0.10 \\
\hline \multicolumn{4}{|l|}{ TASC II classification } \\
\hline$A / B$ & $14(56)$ & $4(31)$ & 0.18 \\
\hline$C / D$ & $11(44)$ & $9(69)$ & \\
\hline \multicolumn{4}{|l|}{ Run off vessel } \\
\hline $0 / 1 / 2 / 3$ & $3 / 8 / 9 / 5$ & $1 / 3 / 8 / 1$ & 0.48 \\
\hline Total stent length (mm) & $164.0 \pm 80.6$ & $215.4 \pm 95.3$ & 0.09 \\
\hline No. stents used & $1.8 \pm 0.9$ & $2.0 \pm 0.8$ & 0.58 \\
\hline Stent diameter $(\mathrm{mm})$ & $6.2 \pm 0.4$ & $6.1 \pm 0.3$ & 0.49 \\
\hline Post-dilatation balloon diameter (mm) & $5.0 \pm 0.0$ & $5.0 \pm 0.0$ & $>0.99$ \\
\hline
\end{tabular}

Data given as mean \pm SD or $n(\%)$.

BMS, bare-metal nitinol stent; PES, paclitaxel-eluting nitinol stent; TASC, Trans-Atlantic Inter-society Consensus.

\section{Serial Volumetric IVUS}

To further investigate the in vivo mechanical behavior of the self-expanding stent and the vascular response in the entire lesion segment, serial volumetric analysis was performed immediately after stent deployment and at 6-month follow-up within the stent and in the persistent margins $(10 \mathrm{~mm}$ proximal and distal to the stent edge). Measurements of vessel, lumen and stent areas were made at 5-mm axial intervals, and vessel, stent, lumen, plaque and neointimal volumes were calculated using Simpson's rule. ${ }^{13}$ For comparison between the 2 stent configurations, mean stent, lumen and NIA were computed as the volume divided by the stent length. ${ }^{14}$ Mean late lumen area loss was defined as mean lumen area immediately after initial deployment minus mean lumen area at follow-up. To evaluate the axial distribution of $\mathrm{NIH}$, we divided each stent into 8 segments and aligned subsections to correct the difference of stent length. Average NIA for each segment was then obtained to analyze the axial distribution.

\section{Endpoints}

The primary endpoint of this study was IVUS findings including stent volume, neointimal volume, and late lumen loss at 6-month follow-up determined on quantitative IVUS analysis. The secondary endpoint of the study was the angiographic restenosis rate at 6-month follow-up.

\section{Statistical Analysis}

Statistical analysis was done using StatView version 5.0 (SAS Institute, Cary, NC, USA). Data are given as mean \pm SD. Con- tinuous variables were examined using unpaired t-test or Mann-Whitney U-test. Categorical variables were compared using chi-squared test or Fisher exact test. The intra- and interobserver variabilities were assessed on linear regression analysis. $\mathrm{P}<0.05$ was considered statistically significant.

\section{Results}

\section{Baseline Characteristics}

A total of 38 de novo SFA lesions from 32 patients were analyzed in this study. BMS were implanted in 25 lesions of 21 patients (BMS group) and PES were deployed in 13 lesions of 11 patients (PES group). Initial procedural success was obtained in all cases and no procedure-related complications were reported both at baseline and at follow-up. The baseline characteristics are listed in Table 1. DAPT was continued during follow-up in almost all cases (96\% in the BMS group and $93 \%$ in the PES group). DAPT with aspirin and clopidogrel was more frequent in the PES group compared to the BMS group (62\% in the PES group vs. $12 \%$ in the BMS group). DAPT with aspirin and cilostazol was more frequent in the BMS group (84\% in the BMS group vs. $31 \%$ in the PES group). Mean lesion length was $142.8 \pm 86.5 \mathrm{~mm}$ in the BMS group and $169.2 \pm 98.0 \mathrm{~mm}$ in the PES group $(\mathrm{P}=0.40)$. Average total stent length tended to be longer in the PES group compared to the BMS group (215.4 $\pm 95.3 \mathrm{~mm}$ vs. $164.0 \pm 80.6 \mathrm{~mm}, \mathrm{P}=0.09)$.

\section{QVA and Stent Fracture}

There was no difference in \%DS of the target lesion before 


\begin{tabular}{|c|c|c|c|}
\hline & BMS ( $n=25)$ & PES ( $n=13)$ & P-value \\
\hline \multicolumn{4}{|l|}{ After initial stenting } \\
\hline Minimum stent area $\left(\mathrm{mm}^{2}\right)$ & $15.7 \pm 1.8$ & $11.4 \pm 2.8$ & $<0.001$ \\
\hline \multicolumn{4}{|l|}{ Reference segment } \\
\hline Proximal EEM area $\left(\mathrm{mm}^{2}\right)$ & $44.9 \pm 16.4$ & $47.0 \pm 20.3$ & 0.75 \\
\hline Proximal lumen area $\left(\mathrm{mm}^{2}\right)$ & $28.0 \pm 13.3$ & $29.0 \pm 14.6$ & 0.84 \\
\hline Distal EEM area $\left(\mathrm{mm}^{2}\right)$ & $34.9 \pm 12.9$ & $27.9 \pm 6.0$ & 0.10 \\
\hline Distal lumen area $\left(\mathrm{mm}^{2}\right)$ & $22.2 \pm 8.7$ & $15.1 \pm 3.3$ & 0.01 \\
\hline Stent expansion ratio & $0.69 \pm 0.20$ & $0.56 \pm 0.18$ & 0.07 \\
\hline Radial stent symmetry index & $0.71 \pm 0.13$ & $0.71 \pm 0.15$ & 0.93 \\
\hline Axial stent symmetry index & $0.64 \pm 0.13$ & $0.54 \pm 0.16$ & 0.07 \\
\hline Stent edge dissection & $14(56)$ & $6(46)$ & 0.73 \\
\hline Tissue protrusion & $5(20)$ & $3(23)$ & $>0.99$ \\
\hline \multicolumn{4}{|l|}{ 6-month follow-up } \\
\hline Minimum stent area $\left(\mathrm{mm}^{2}\right)$ & $22.0 \pm 2.8$ & $15.7 \pm 3.1$ & $<0.001$ \\
\hline Minimum lumen area $\left(\mathrm{mm}^{2}\right)$ & $11.5 \pm 5.2$ & $11.9 \pm 3.7$ & 0.81 \\
\hline Maximum \%NIH & $57.2 \pm 18.1$ & $39.0 \pm 18.9$ & $<0.01$ \\
\hline Stent expansion ratio & $0.96 \pm 0.27$ & $0.77 \pm 0.30$ & 0.06 \\
\hline Radial stent symmetry index & $0.82 \pm 0.09$ & $0.79 \pm 0.13$ & 0.32 \\
\hline Axial stent symmetry index & $0.68 \pm 0.11$ & $0.61 \pm 0.17$ & 0.14 \\
\hline Stent edge dissection & $8(32)$ & $4(31)$ & $>0.99$ \\
\hline Thrombus & $0(0)$ & $2(15)$ & 0.11 \\
\hline
\end{tabular}

Data given as mean \pm SD or $\mathrm{n}(\%)$.

EEM, external elastic membrane; IVUS, intravascular ultrasound; $\mathrm{NIH}$, neointimal hyperplasia. Other abbreviations as in Table 1.

\begin{tabular}{|lccc|}
\hline Table 3. Volumetric IVUS Analysis & & & \\
& BMS $(\mathbf{n}=\mathbf{2 5})$ & PES $(\mathbf{n}=\mathbf{1 3})$ & P-value \\
After initial stenting & & & \\
Stent volume $\left(\mathrm{mm}^{3}\right)$ & $3,312 \pm 1,714$ & $3,584 \pm 1,697$ & 0.66 \\
Mean stent area $\left(\mathrm{mm}^{2}\right)$ & $20.0 \pm 2.0$ & $16.3 \pm 1.7$ & $<0.001$ \\
At 6-month follow-up & & & \\
Stent volume $\left(\mathrm{mm}^{3}\right)$ & $4,816 \pm 2,829$ & $4,768 \pm 2,278$ & 0.96 \\
Mean sent area $\left(\mathrm{mm}^{2}\right)$ & $28.2 \pm 3.8$ & $21.8 \pm 2.9$ & $<0.001$ \\
Lumen volume $\left(\mathrm{mm}^{3}\right)$ & $3,052 \pm 2,118$ & $4,084 \pm 2,093$ & 0.16 \\
Mean lumen area $\left(\mathrm{mm}^{2}\right)$ & $18.0 \pm 5.5$ & $18.5 \pm 3.4$ & 0.75 \\
Neointimal volume $\left(\mathrm{mm}^{3}\right)$ & $1,764 \pm 1,384$ & $685 \pm 348$ & $<0.01$ \\
Mean neointimal area $\left(\mathrm{mm}^{2}\right)$ & $10.2 \pm 4.1$ & $3.3 \pm 1.0$ & $<0.001$ \\
Mean late lumen area loss $\left(\mathrm{mm}^{2}\right)$ & $2.1 \pm 4.7$ & $-2.3 \pm 3.7$ & $<0.05$ \\
\hline
\end{tabular}

Data given as mean \pm SD or $\mathrm{n}(\%)$.

Abbreviations as in Tables 1,2.

EVT between the 2 groups $(80.1 \pm 19.6 \%$ in the BMS group and $87.6 \pm 18.1 \%$ in the PES group, $\mathrm{P}=0.26$ ) on $\mathrm{QVA}$ analysis. Six months after stent implantation, follow-up angiography was performed in all lesions. On QVA analysis, in-stent \%DS at follow-up tended to be lower in the PES group compared to the BMS group $(23.2 \pm 10.7 \%$ vs. $37.2 \pm 10.5 \%, \mathrm{P}=0.06$.) Angiographic restenosis was observed in 6 lesions $(24 \%)$ in the BMS group and in 1 lesion (8\%) in the PES group $(\mathrm{P}=0.39)$. Two stent fractures (15\%; type 1 fracture and type 3 fracture) were detected in the PES group after 6 months after stent implantation. We detected no stent fracture in the BMS group.

Intra- and Inter-Observer Variability of IVUS Measurements IVUS measurements of stent area, lumen area, and NIA had excellent intra- and inter-observer reproducibility. In the intra- observer variability analysis, stent area $(\mathrm{r}=0.997, \mathrm{P}<0.0001)$, lumen area $(\mathrm{r}=0.952, \mathrm{P}<0.0001)$, and NIA $(\mathrm{r}=0.932, \mathrm{P}<0.0001)$ measurements were highly correlated. In the inter-observer variability analysis, stent area $(\mathrm{r}=0.994, \mathrm{P}<0.0001)$, lumen area $(\mathrm{r}=0.938, \mathrm{P}<0.0001)$, and NIA $(\mathrm{r}=0.933, \mathrm{P}<0.0001)$ measurements were also highly correlated.

\section{Serial 2-D IVUS}

Serial 2-D IVUS findings are summarized in Table 2. MSA was significantly smaller in the PES group than in the BMS group both at the initial procedure and at 6-month follow-up $\left(11.4 \pm 2.8 \mathrm{~mm}^{2}\right.$ vs. $15.7 \pm 1.8 \mathrm{~mm}^{2}, \mathrm{P}<0.001$; and $15.7 \pm 3.1 \mathrm{~mm}^{2}$ vs. $22.0 \pm 2.8 \mathrm{~mm}^{2}, \mathrm{P}<0.001$, respectively). There was no significant difference in MLA, however, at 6-month follow-up between the 2 groups because the PES group had significantly 

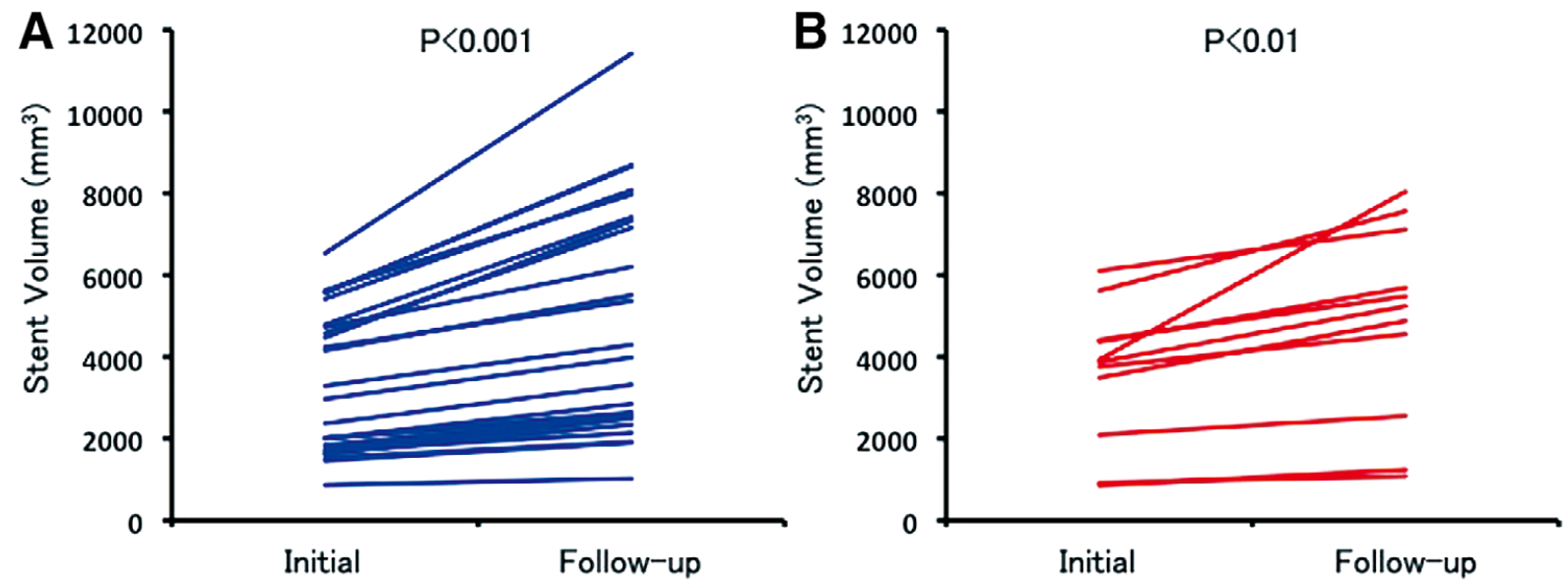

Figure 1. Change in absolute stent volume between initial deployment and follow-up in the (A) self-expanding bare-metal nitinol stent and (B) self-expanding paclitaxel-eluting nitinol stent groups during 6 months.

smaller \%NIA at 6-month follow-up compared to the BMS group $(39.0 \pm 18.9 \%$ vs. $57.2 \pm 18.1 \%, \mathrm{P}<0.01)$. There were no significant differences in stent expansion ratio, radial stent symmetry indices, and axial stent symmetry indices between the 2 groups. During follow-up, MSA has become larger in both groups (from $15.7 \pm 1.8 \mathrm{~mm}^{2}$ to $22.0 \pm 2.8 \mathrm{~mm}^{2}$ in the BMS group, $\mathrm{P}<0.001$; and from $11.4 \pm 2.8 \mathrm{~mm}^{2}$ to $15.7 \pm 3.1 \mathrm{~mm}^{2}$ in the PES group, $\mathrm{P}<0.001$, respectively). Similarly, stent expansion ratio (from $0.69 \pm 0.20$ to $0.96 \pm 0.27$ in the BMS group, $\mathrm{P}<0.001$; and from $0.56 \pm 0.18$ to $0.77 \pm 0.30$ in the PES group, $\mathrm{P}<0.01$, respectively) and radial stent symmetry indices (from $0.71 \pm 0.13$ to $0.82 \pm 0.09$ in the BMS group, $\mathrm{P}<0.001$; and from $0.71 \pm 0.15$ to $0.79 \pm 0.13$ in the PES group, $\mathrm{P}<0.01$, respectively) became larger during the follow-up period in both groups.

\section{Serial Volumetric IVUS}

Serial volumetric IVUS findings are presented in Table 3. Mean stent area after initial procedure and at 6-month followup were significantly smaller in the PES group compared to the BMS group $\left(16.3 \pm 1.7 \mathrm{~mm}^{2}\right.$ vs. $20.0 \pm 2.0 \mathrm{~mm}^{2}, \mathrm{P}<0.001$; and $21.8 \pm 2.9 \mathrm{~mm}^{2}$ vs. $28.2 \pm 3.8 \mathrm{~mm}^{2}, \mathrm{P}<0.001$, respectively). BMS increased $41.0 \%$ in mean stent area during the follow-up period (from $20.0 \pm 2.0 \mathrm{~mm}^{2}$ to $28.2 \pm 3.8 \mathrm{~mm}^{2}, \mathrm{P}<0.001$ ), and PES increased $35.6 \%$ in mean stent area (from $16.3 \pm 1.7 \mathrm{~mm}^{2}$ to $\left.21.8 \pm 2.9 \mathrm{~mm}^{2}, \mathrm{P}<0.001\right)$. The degree of increase in mean stent area during the follow-up period was similar between the BMS and PES groups $(41.0 \%$ and $35.6 \%, \mathrm{P}=0.41)$. Stent volume also increased during the follow-up period in both groups (from $3,312 \pm 1,714 \mathrm{~mm}^{3}$ to $4,816 \pm 2,829 \mathrm{~mm}^{3}$ in the BMS group, $\mathrm{P}<0.001$, and from $3,584 \pm 1,697 \mathrm{~mm}^{3}$ to $4,768 \pm 2,278 \mathrm{~mm}^{3}$ in the PES group, $\mathrm{P}<0.01$; Figure 1 ). Mean NIA was significantly smaller in the PES group compared to the BMS group $\left(3.3 \pm 1.0 \mathrm{~mm}^{2}\right.$ vs. $\left.10.2 \pm 4.1 \mathrm{~mm}^{2}, \mathrm{P}<0.001\right)$. As a result, mean late lumen area loss was smaller in the PES group compared to the BMS group $\left(-2.3 \pm 3.7 \mathrm{~mm}^{2}\right.$ vs. $2.1 \pm 4.7 \mathrm{~mm}^{2}, \mathrm{P}<0.05$; Figure 2). The axial distribution pattern of NIH is shown in Figure 3. Although NIH was evenly distributed throughout the entire stented length in the BMS group, there was a trend to larger amount of NIH at the distal portion of the stented segment in the PES group. In the PES group, average NIA at the

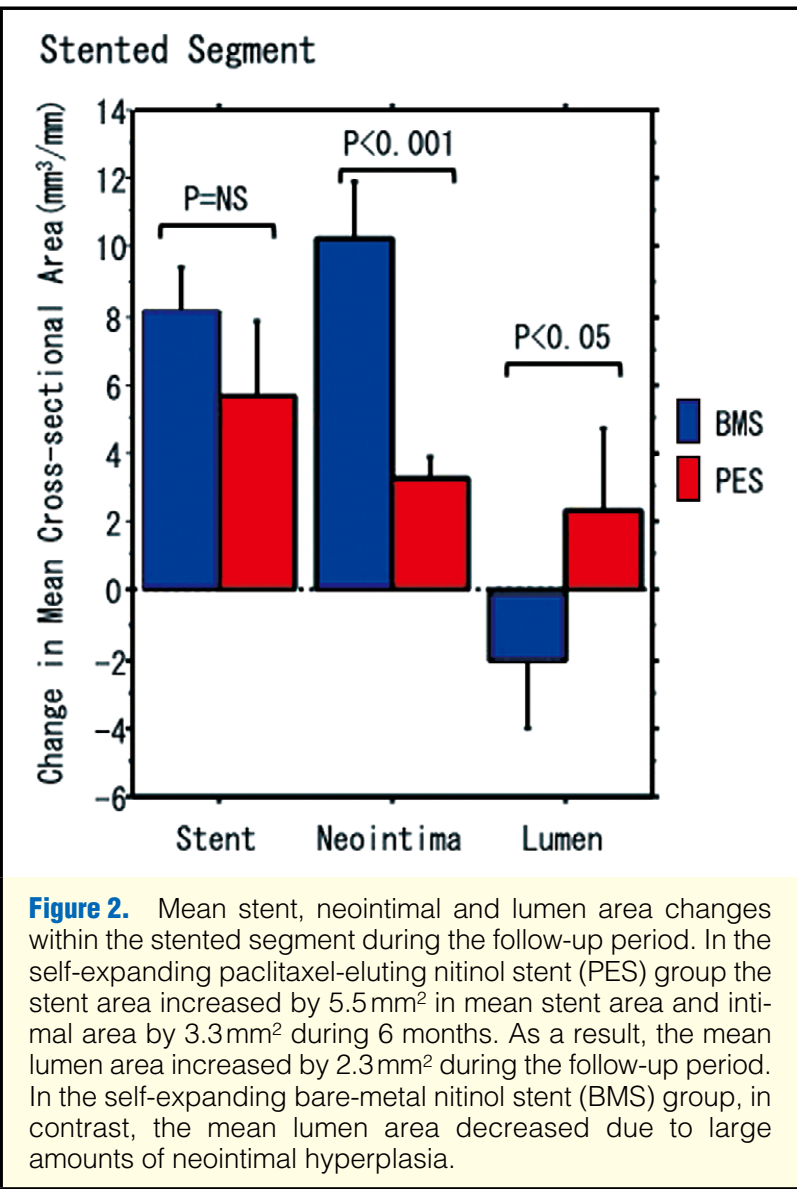

distal 4 segments tended to be larger than that at the proximal 4 segments $\left(3.6 \pm 2.5 \mathrm{~mm}^{2}\right.$ vs. $\left.2.9 \pm 2.1 \mathrm{~mm}^{2}, \mathrm{P}=0.09\right)$.

\section{Persistent Margins}

Twenty margins for the BMS group and 9 margins for the PES group were acceptable for serial volumetric analysis. Mean 

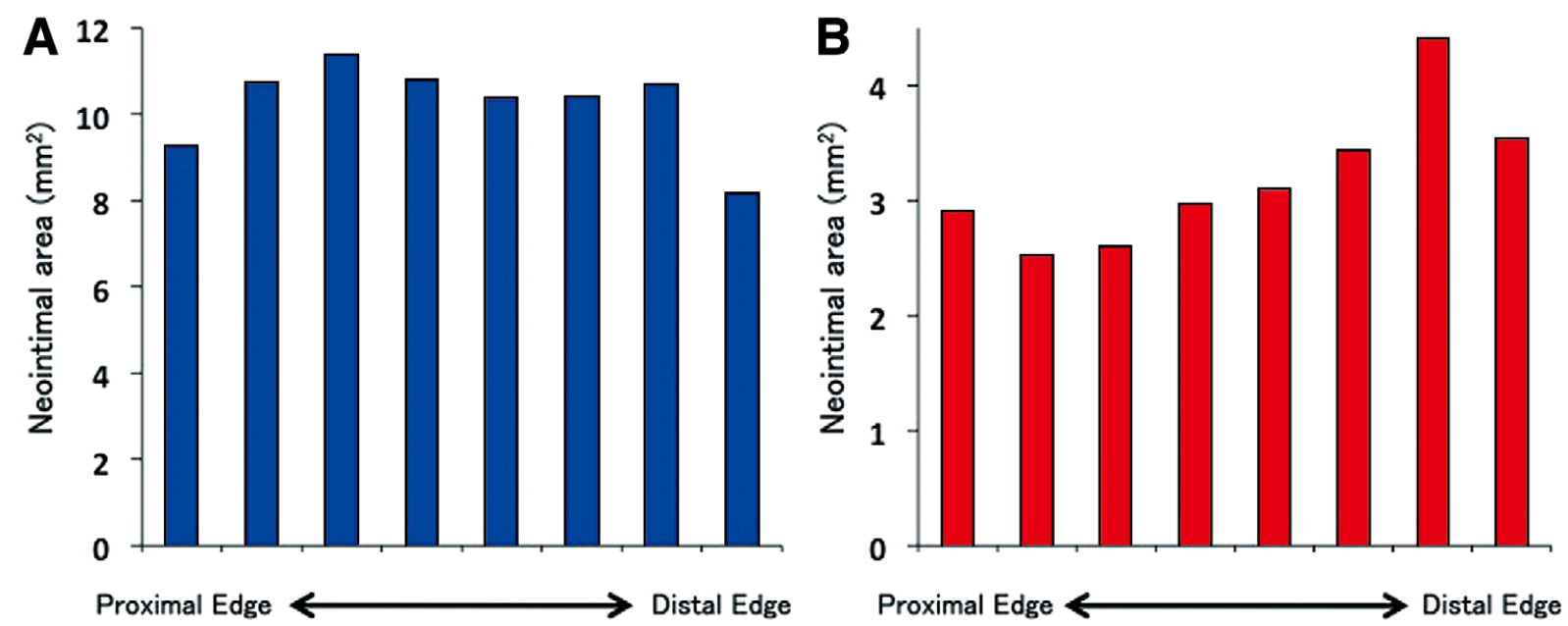

Figure 3. Axial distribution of neointimal hyperplasia $(\mathrm{NIH})$ measured on intravascular ultrasound over the length of the stent. (A) $\mathrm{NIH}$ was evenly distributed throughout the length of the self-expanding bare-metal nitinol stent (BMS). (B) Axial distribution of $\mathrm{NIH}$ of the self-expanding paclitaxel-eluting nitinol stent was shifted to the distal segments, and average NIH was significantly lower compared with the BMS.

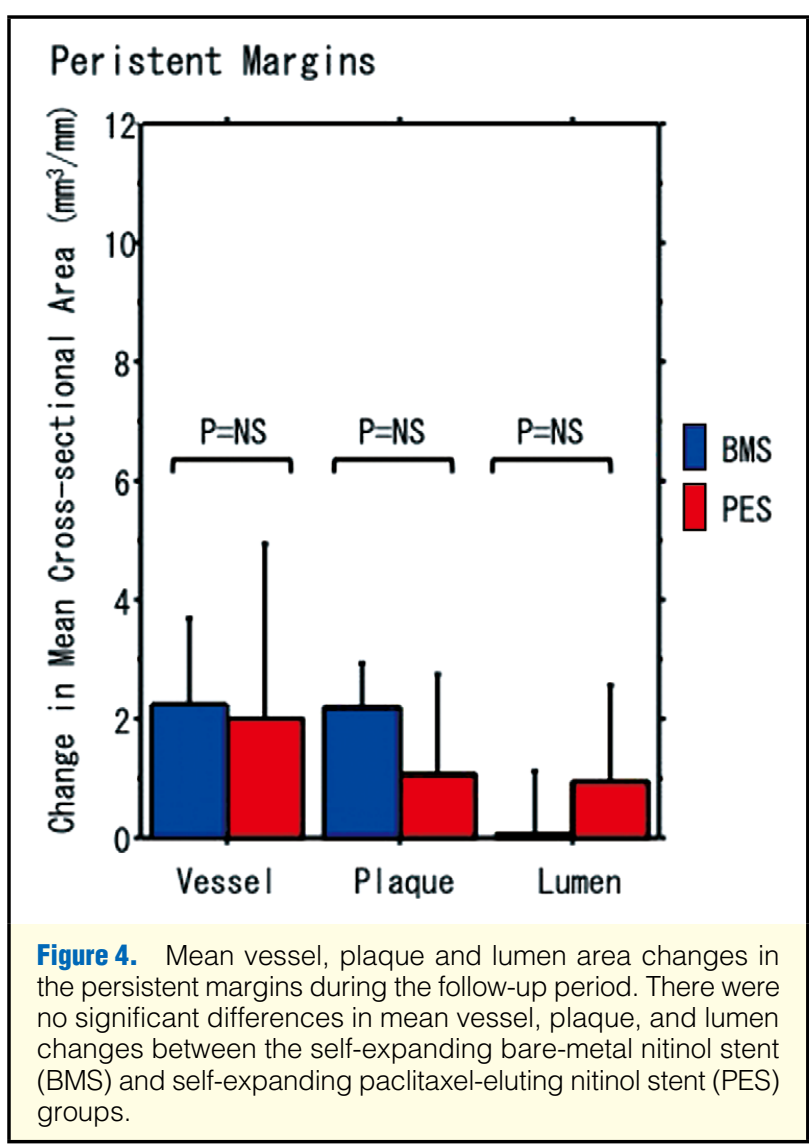

EEM, plaque, and lumen area at persistent margins were similar between the BMS group and the PES group both after initial stent deployment and at 6-month follow-up (Figure 4). Although mean EEM area at the proximal reference did not change, mean EEM area at the distal reference slightly increased during the follow-up period (from $33.3 \pm 11.7 \mathrm{~mm}^{2}$ to $\left.35.7 \pm 12.5 \mathrm{~mm}^{2}, \mathrm{P}<0.001\right)$. The incidence of stent edge dissection after initial stent deployment and at follow-up was similar between the 2 groups (Table 2). Among 20 dissections identified on IVUS at the initial stent deployment, 8 dissections (40\%) resolved and 12 dissections (60\%) persisted during the follow-up period. No significant differences in the natural history of stent edge dissection existed between the 2 groups.

\section{Discussion}

To the best of our knowledge, this is the first study to report on chronic vascular response to the implantation of PES and BMS in SFA lesions using serial volumetric IVUS. The main findings of this study are as follows: (1) PES increased $35.6 \%$ in overall stent volume and BMS, $41.0 \%$; (2) a significantly smaller amount of NIH at 6 months after stent implantation was identified in the PES group than in the BMS group; and (3) the vascular response at persistent margin was similar between the 2 groups.

Although BMS implantation in the SFA lesion has improved clinical outcome compared to balloon angioplasty, previous studies reported that the restenosis rate was still high: $32 \%$ in the FAST trial, ${ }^{15} 34 \%$ in the ASTRON trial, ${ }^{16}$ and $36 \%$ in the ABSOLUTE trial, ${ }^{4}$ respectively. In the coronary artery lesions, drug-eluting stents (DES) have successfully decreased the rate of in-stent restenosis (ISR) and target lesion revascularization (TLR) compared with BMS. ${ }^{17-19}$ In the lower extremity, however, sirolimus-eluting stent failed to demonstrate superiority on prevention of ISR compared to BMS. ${ }^{20}$ In contrast, EVT with PES is associated with lower TLR rate and higher patency rate. ${ }^{7}$ Tepe et al reported that paclitaxel-coated balloon has a lower late lumen loss and TLR rate. ${ }^{21}$ In the SFA lesion, paclitaxel might be more effective compared to sirolimus for prevention of ISR.

Several studies have reported the safety and efficacy of EVT with PES for the SFA lesions. ${ }^{7,8}$ Dake et al reported that event- 
free survival rate at 6 months after EVT with PES was 97\%, and clinically driven TLR were performed in $10 \% .^{7}$ In that study, average lesion length was $66.4 \mathrm{~mm}$, and $27 \%$ of the lesions were total occlusions in the PES group. In the current study, lesion length was longer (169.2 $\mathrm{mm}$ in the PES group) and the prevalence of chronic total occlusion (62\% in the PES group) was higher than in previous studies. Despite a complicated lesion background, the present result is similar to that of previous studies.

A previous study reported that NIH is the arterial wall's healing response to mechanical injury. ${ }^{22}$ In an experimental study, Forrester et al proposed a paradigm for neointimal growth as a general wound-healing response. ${ }^{23}$ Platelet aggregation, inflammatory cell infiltration, release of growth factors, medial smooth muscle cell (SMC) modulation and proliferation, proteoglycan deposition, and extracellular matrix remodeling were identified as the major indicators in the temporal sequence of this response. A previous human study of BMS noted that self-expanding stents had a $23.6 \%$ increase in stent volume between the procedure and 6-month follow-up. ${ }^{14}$ These reports suggest that chronic continuous mechanical injury by nitinol self-expanding stents to vessel walls might be associated with an increase in subsequent NIH. In the current study, BMS increased $41.0 \%$ in mean stent area during the follow-up period (from $20.0 \pm 2.0 \mathrm{~mm}^{2}$ to $28.2 \pm 3.8 \mathrm{~mm}^{2}$, $\mathrm{P}<0.001$ ), and PES increased $35.6 \%$ in mean stent area (from $16.3 \pm 1.7 \mathrm{~mm}^{2}$ to $\left.21.8 \pm 2.9 \mathrm{~mm}^{2}, \mathrm{P}<0.001\right)$. The degree of the increase in mean stent area during the follow-up period was similar between the 2 groups $(41.0 \%$ and $35.6 \%, P=0.41)$. The degree of increase in stent volume was also similar between the 2 groups. These results suggest that the radial force and the continuous mechanical injury from the stent were similar between BMS and PES. It was reported that paclitaxel induces arrest of the cell cycle in mitosis and inhibition of SMC migration. $^{24,25}$ In the current study, paclitaxel may have attenuated $\mathrm{NIH}$ by arresting the cell cycle and inhibiting SMC migration, which would have led to a smaller amount of NIH in the PES group than in the BMS group.

In previous angioscopic assessment the prevalence of thrombus and yellow plaque was similar between the BMS group and the PES group. ${ }^{26}$ In line with this, the prevalence of thrombus was similar between the 2 groups in the current study. Stent edge dissection could be induced by excessive vessel stretch during stent implantation and post-dilation. Previous IVUS study suggested that stent edge dissection without flow-limitation in the coronary artery is not associated with an increase in future adverse events, including ISR. ${ }^{27}$ In addition, another IVUS study indicated that $75 \%$ of coronary stent edge dissections resolved without changes in vessel, lumen, and plaque area 6 months after the stent implantation. ${ }^{28}$ In accordance with previous studies, in the present study approximately half of stent edge dissections resolved during the 6-month follow-up period both in the PES and BMS groups. Moreover, no edge restenosis at follow-up was detected for lesions in which edge dissection was identified at the baseline procedure. Thus, the clinical impact of minor edge dissections visible on IVUS seems to be minimal.

\section{Study Limitations}

This study was a retrospective analysis of data from a singlecenter, small-number, and non-randomized prospective study. Prospective randomized multi-center studies are required to reconfirm the results in a larger number of patients. Follow-up angiography and IVUS were performed at 6 months after EVT. Further long-term follow-up, however, might be neces- sary to evaluate NIH after DES implantation. ${ }^{29-31}$ Because lesion length was too long (142.8 $\mathrm{mm}$ in the BMS group and $169.2 \mathrm{~mm}$ in the PES group), the IVUS pullback through the SFA lesion was performed manually. We recognize that the mechanisms leading to restenosis are different between BMS and DES. No qualitative comparison of neointima on IVUS findings between the BMS group and the PES group was attempted, however, due to the limited number of lesions with ISR in the PES group.

\section{Conclusions}

DES is safe and effective for treatment of SFA lesions in the short term. EVT with PES might decrease NIH associated with ISR.

\section{Acknowledgments}

The authors thank the staff of the catheterization laboratory at Hyogo College of Medicine for their excellent assistance during the study.

\section{References}

1. Rowe VL, Lee W, Weaver FA, Etzioni D. Pattern of treatment for peripheral arterial disease in the United States: 1996-2005. J Vasc Surg 2009; 49: 910-917.

2. Dormandy JA, Rutherford RB. Management of peripheral arterial disease (PAD): TASC Working Group: TransAtlantic Inter-Society Consensus (TASC). J Vasc Surg 2000; 31: S1-S296.

3. Norgren L, Hiatt WR, Dormandy JA, Nehler MR, Haris KA, Fowkes FG; TASC II Working Group. Inter-Society Consensus for the Management of Peripheral Arterial Disease (TASC II). J Vasc Surg 2007; 45 (Suppl S): S5-S67.

4. Schillinger M, Sabeti S, Loewe C, Dick P, Amighi J, Mlekusch W, et al. Balloon angioplasty versus implantation of nitinol stents in the superficial femoral artery. N Engl J Med 2006; 354: 1879-1888.

5. Vogel TR, Shindelman LE, Nackman GB, Graham AM. Efficacious use of nitinol stents in the femoral and popliteal arteries. J Vasc Surg 2003; 38: $1178-1184$.

6. Schillinger M, Sabeti S, Dick P, Amighi J, Mlekusch W, Schlager O, et al. Sustained benefit at 2 years of primary femoropopliteal stenting compared with balloon angioplasty with optional stenting. Circulation 2007; 115: 2745-2749.

7. Dake MD, Ansel GM, Jaff MR, Ohki T, Saxon RR, Smouse HB, et al. Paclitaxel-eluting stents show superiority to balloon angioplasty and bare metal stents in femoropopliteal disease: Twelve-month Zilver PTX randomized study results. Circ Cardiovasc Interv 2011; 4: 495-504.

8. Dake MD, Ansel GM, Jaff MR, Ohki T, Saxon RR, Smouse HB, et al. Sustained safety and effectiveness of paclitaxel-eluting stents for femoropopliteal lesions: 2-year follow-up from the Zilver PTX randomized and single-arm clinical studies. J Am Coll Cardiol 2013; 61: $2417-2427$.

9. Kawarada O, Higashimori A, Noguchi M, Waratani N, Yoshida M, Fujihara M, et al. Duplex criteria for in-stent restenosis in the superficial femoral artery. Catheter Cardiovasc Interv 2013; 81: E199E205.

10. Cheneau E, Leborgne L, Mintz GS, Kotani J, Pichard AD, Satler LF, et al. Predictors of subacute stent thrombosis: Results of a systematic intravascular ultrasound study. Circulation 2003; 108: 43-47.

11. Mintz GS, Nissen SE, Anderson WD, Bailey SR, Erbel R, Fitzgerald PJ, et al. American College of Cardiology Clinical Expert Consensus Document on Standards for Acquisition, Measurement and Reporting of Intravascular Ultrasound Studies (IVUS): A report of the American College of Cardiology Task Force on Clinical Expert Consensus Documents. J Am Coll Cardiol 2001; 37: 1478-1492.

12. Fukuda D, Kawarabayashi T, Tanaka A, Nishibori Y, Taguchi H, Nishida Y, et al. Lesion characteristics of acute myocardial infarction: An investigation with intravascular ultrasound. Heart 2001; 85: 402-406.

13. Dussaillant GR, Mintz GS, Pichard AD, Kent KM, Satler LF, Popma JJ, et al. Small stent size and intimal hyperplasia contribute to restenosis: A volumetric intravascular ultrasound analysis. J Am Coll Cardiol 1995; 26: 720-724.

14. Kobayashi Y, Honda Y, Christie GL, Teirstein PS, Bailey SR, Brown $\mathrm{CL}$ 3rd, et al. Long-term vessel response to a self-expanding coro- 
nary stent: A serial volumetric intravascular ultrasound analysis from the ASSURE Trial: A stent vs. stent ultrasound remodeling evaluation. J Am Coll Cardiol 2001; 37: 1329-1334.

15. Krankenberg H, Schlüter M, Steinkamp HJ, Bürgelin K, Scheinert $\mathrm{D}$, Schulte KL, et al. Nitinol stent implantation versus percutaneous transluminal angioplasty in superficial femoral artery lesions up to $10 \mathrm{~cm}$ in length: The femoral artery stenting trial (FAST). Circulation 2007; 116: $285-292$.

16. Dick P, Wallner H, Sabeti S, Loewe C, Mlekusch W, Lammer J, et al. Balloon angioplasty versus stenting with nitinol stents in intermediate length superficial femoral artery lesions. Catheter Cardiovasc Interv 2009; 74: 1090-1095.

17. Moses JW, Leon MB, Popma JJ, Fitzgerald PJ, Holmes DR, O'Shaughnessy C, et al. Sirolimus-eluting stents versus standard stents in patients with stenosis in a native coronary artery. $N$ Engl $J$ Med 2003; 349: 1315-1323.

18. Stettler C, Wandel S, Allemann S, Kastrati A, Morice MC, Schomig A, et al. Outcomes associated with drug-eluting and bare-metal stents: A collaborative network meta-analysis. Lancet 2007; 370: 937-948.

19. Stone GW, Ellis SG, Cox DA, Hermiller J, O'Shaughnessy C, Mann JT, et al. A polymer-based, paclitaxel-eluting stent in patients with coronary artery disease. $N$ Engl J Med 2004; 350: 221-231.

20. Duda SH, Pusich B, Richter G, Landwehr P, Oliva VL, Tielbeek A, et al. Sirolimus-eluting stents for the treatment of obstructive superficial femoral artery disease: Six-month results. Circulation 2002; 106: $1505-1509$.

21. Tepe G, Zeller T, Albrecht T, Heller S, Schwarzwälder U, Beregi JP, et al. Local delivery of paclitaxel to inhibit restenosis during angioplasty of the leg. N Engl J Med 2008; 358: 689-699.

22. Costa MA, Simon DI. Molecular basis of restenosis and drug-eluting stents. Circulation 2005; 111: 2257-2273.
23. Forrester JS, Fishbein M, Helfant R, Fagin J. A paradigm for restenosis based on cell biology: Clues for the development of new preventive therapies. J Am Coll Cardiol 1991; 17: 758-769.

24. Sollott SJ, Cheng L, Pauly RR, Jenkins GM, Monticone RE, Kuzuya $\mathrm{M}$, et al. Taxol inhibits neointimal smooth muscle cell accumulation after angioplasty in the rat. J Clin Invest 1995; 95: 1869-1876.

25. Axel DI, Kunert W, Goggelmann C, Oberhoff M, Herdeg C, Kuttner A, et al. Paclitaxel inhibits arterial smooth muscle cell proliferation and migration in vitro and in vivo using local drug delivery. Circulation 1997; 96: 636-645.

26. Ishihara $\mathrm{T}$, Iida $\mathrm{O}$, Awata $\mathrm{M}$, Nanto K, Nanto S, Uematsu M. Angioscopic assessment of early phase arterial repair after paclitaxel-coated nitinol drug-eluting stent implantation in the superficial femoral artery. Circ J 2013; 77: 1838-1843.

27. Schroeder S, Baumbach A, Mahrholdt H, Haase KK, Oberhoff M, Herdeg $\mathrm{C}$, et al. The impact of untreated coronary dissections on acute and long-term outcome after intravascular ultrasound guided PTCA. Eur Heart J 2000; 21: 137-145.

28. Sheris SJ, Canos MR, Weissman NJ. Natural history of intravascular ultrasound-detected edge dissections from coronary stent deployment. Am Heart J 2000; 139: 59-63.

29. Yang TH, Kim DI, Jin HY, Cho YW, Chung SR, Kim DK, et al. "Angiographic late catch-up" phenomenon after sirolimus-eluting stent implantation. Int J Cardiol 2012; 160: 48-52.

30. Collet CA, Costa JR, Abizaid A, Chamié D, Staico R, Costa R, et al. Assessing the temporal course of neointimal hyperplasia formation after different generations of drug-eluting stents. JACC Cardiovasc Interv 2011; 4: 1067-1074.

31. Ejiri K, Ishihara M, Dai K, Miki T, Inoue I, Kawagoe T, et al. Threeyear follow-up of sirolimus-eluting stents vs. bare metal stents for acute myocardial infarction. Circ J 2012; 76: 65-70. 